\title{
RADICAL SURGERY FOR LIVER HYDATID CYST
}

\author{
Hadj Omar El Malki, 1,2, Amine Souadka, 1,3 Badr Serji, 1 Amine Benkabbou,1 Raouf Mohsine,1 Lahsen Ifrine,1 \\ Abdelkader Belkouchi.1 \\ 1University Mohammed Vth Rabat, Medical School, Ibn Sina Hospital, Surgery Department 'A', Rabat Morocco. \\ 2Medical Centre of Clinical Trials and Epidemiological Study and Biostatistical Clinical Research and Epidemiological \\ Laboratory, Medical School, University Mohammed Vth Rabat, Rabat Morocco. \\ 3University Mohammed Vth Rabat, Medical School, National Institut of Oncology, Surgery Department Rabat Morocco.
}

\begin{abstract}
Background and Aims: Surgery is the basic treatment for liver hydatid cyst (LHC). Radical procedures (pericystectomy (PK) and hepatic resection (HR)) offers better results in selected cases than conservative approaches. The aims of this study were to evaluate the results of Radical surgery for LHC and to determine witch of these two procedures is safe in experienced hepato-biliary surgical unit in endemic countries.

Methods: A retrospective cohort study of 143 patients with liver hydatid cyst who underwent radical procedures at a single surgical department in an endemic country were reviewed. Mortality, morbidity and recurrence rates have been analyzed.

Results: Thirty two patients $(22.4 \%)$ had a HR and 111 patients $(77.6 \%)$ had a PK. Mortality rate was $1.4 \%(n=2)$ in HR group. Overall morbidity rate was $18.9 \%$ and $28.1 \%$ respectively in PK and $\mathrm{HR}$ group ( $p=0.26$ ). Postoperative bleeding occurred in $1.8 \%$ in PK group vs $3.1 \%$ in HR group $(p=0.535)$ and specific LHC operative complication occurred in $17.1 \%$ in PK group vs $28.1 \%$ in HR group ( $\mathrm{p}=.167$ ).

Recurrence rate of LHC was $6.3 \%$ in PK group vs $6.6 \%$ in HR group ( $\mathrm{p}=0.999$ ) after a median follow up of 108 months (54-144) vs 89 months (44-135) respectively.

Conclusion: Radical surgery for LHC is safe. Each of PK and HR had a specific indication. A good screening of patient's guarantied a good outcome.
\end{abstract}

Key words: Liver, Hydatid Cyst, Radical Surgery.

\section{Corresponding author:}

Dr H. O. El Malki, Imm 4 App 4 Résidence "Les Pins”' Guiche Oudaya Témara, Morocco.

Phone : +212661215977.

E-mail: oelmalki@hotmail.com

Copyright (C) 2012- 2014. El Malki H.O. and al. This is an open access article published under Creative Commons Attribution-NonCommercial-NoDerivs 4.0 International Public License (CC BY-NC-ND). This license allows others to download the articles and share them with others as long as they credit you, but they can't change them in any way or use them commercially.

\section{INTRODUCTION}

Hydatid disease continues to be a major health problem in sheep-raising areas. Hydatid Cyst grows in the liver in $77 \%$ of cases. [1, 2]. Larvae of Echinococcus granulosus cross the intestinal wall and via the portal system migrate to the liver, where they are transformed into cysts. Currently, four therapeutic options are available to manage hydatid disease of the liver: surgery, chemotherapy with benzimidazole compounds, interventional methods: radiology (percutaneous needle aspiration, radiofrequency) and endoscopical approaches and follow-up without treatment. To date there is no consensus attesting for the best attitude, however, surgery remains the basic and the gold standard treatment for liver hydatid cyst.

Some controversies still exist regarding the most appropriate surgical technique, which can definitely eliminate the parasite with a lower morbidity and mortality rate and a negligible recurrence rate. Current thinking tends to opposite radical and conservative surgery. Most surgical studies demonstrate that both mortality and morbidity rate of these two approaches are similar. [1-3] Commonly, mortality, morbidity and recurrence rates range respectively from 0 to $6.5 \%, 4,510 \%$ to $29.5 \%$ [5-7] and 0 to $25 \%$.[8-11] Recent advances in liver surgery during the last decade, with all new technological development help to ensure safe 
aggressive liver resection in selected patients especially in non-malignant disease. Even though many authors recommend radical surgery in LHC, no study demonstrate evident benefit comparing to conservative surgery. Hydatid disease remains a major health problem in sheep-raising areas. Endemic areas are mostly in low-income countries and/or wide and extended territory. Providing care and geographic distribution of tertiary center are not equal. Advanced hepatobiliary surgical unit can not be added anywhere. There is no doubt that radical surgery for liver hydatid cyst by expert surgeons in dedicated centers is safe. [13] Purposes of this study were to assess results and safety of radical approach in management of liver hydatid cysts and compare the results of both $\mathrm{PK}$ and HR technique in LHC.

\section{MATERIALS AND METHODS}

Patients who underwent radical surgery for liver hydatid cyst were identified from an ambispective "liver hydatid cyst" database, from January 1990 to December 2010 in a single tertiary hepatobiliary surgical unit, in endemic disease country. At the admission, the diagnosis of the LHC was established by clinical history, clinical examination and abdominal ultrsonography (US) for all patients. Serological tests were not routinely used. Abdominal computed tomography was performed on patients showing multiple cysts at US or recurrence of Hydatid disease.

Radical approach was defined as an anatomical liver resection or, whenever possible, a total pericystectomy. Liver was transected by the clampcrush technique and haemostasis was achieved using sutures or bipolar coagulation. The whole cyst was removed (pericyst) with adjacent healthy liver tissue. Complete cyst resection was performed either by opening its cavity (open cyst) or not (closed cyst) according to cyst size, topography and surgeon's preference. In the open-cyst technique, all protective measures were applied to prevent intra-abdominal seeding of protoscolices (protection and scolicidal agents). 1, 14, 15 All procedures were performed by open laparotomy. Demographic data, cyst characteristics, surgical procedure were recorded. Operative mortality, defined as death regardless of the cause within 30 first postoperative days in or out of hospital; hydatid cyst-specific surgical complications "deep abdominal complications (DAC)" [5] and cyst recurrence were the aim endpoints of the study. [11] Statistical methods: Continuous variables were presented as mean value \pm standard deviation or median interquartile range (IQR) and categorical variables were expressed as frequency and percentage. We have conducted an univariable association between each item and the type of radical surgery (pericystectomy and hepatic resection) with the $\chi 2$ test or Fisher exact test. A Mann-Whitney U-test was used to compare nonnormally distributed continuous variable. Tests were always two-sided and significance was considered from a P value less than 0.05 .

Recurrence rates have been analyzed by the Kaplan-Meier method for patients undergoing surgery and apparently disease-free at the time of discharge from the hospital. Differences in recurrence between subgroups of patients were evaluated using the log-rank test. SPSS ${ }^{\circledR}$ version 13 statistical software package was used for statistical analysis (IBM, Armonk, New York, USA).

\section{RESULTS}

One hundred forty three patients underwent radical surgery for liver hydatid cyst. There were 91 women $(63.6 \%)$ and 52 men $(36.4 \%)$ with a mean age of $39.53 \pm 14.88$ years. Forty eight patients $(34,3 \%)$ had previously undergone surgery for hydatid disease in various localizations, previous hydatid liver surgery in 25 patients and hydatid lung surgery in 24 patients. Although 24 patients $(16.8 \%)$ were totally asymptomatic. The most common symptom was pain on the right-upper quadrant $(34.2 \%)$ and the most common finding on the physical examination was a palpable mass at this location (42\%). The median duration of symptoms and signs $(\mathrm{n}=141)$ was 5 months (interquartile range 25, 75: 2 months; 12 months). Demographic and clinical features of these patients are shown in Tables I and II. 


\section{Un.JMSR}

Journal of Medical and Surgical Research

Table I: Patient's demographics and cyst's distribution in the hepatic lobes.

\begin{tabular}{|c|c|c|c|}
\hline Variables & $\begin{array}{r}\text { Number of evaluated } \\
\text { patients }\end{array}$ & $\begin{array}{r}\text { Number of } \\
\text { subject }\end{array}$ & $\%$ \\
\hline Age (years) & 143 & & \\
\hline$\leq 40$ & & 79 & 55.2 \\
\hline $41-60$ & & 54 & 37.8 \\
\hline$\geq 61$ & & 10 & 7.0 \\
\hline Sex & 143 & & \\
\hline Female & & 91 & 63.6 \\
\hline Male & & 52 & 36.4 \\
\hline Past history of hydatidosis & 143 & & \\
\hline No & & 94 & 65.7 \\
\hline Liver & & 25 & 17.5 \\
\hline Lung & & 24 & 16.8 \\
\hline Number of cysts & 140 & & \\
\hline One & & 86 & 61,4 \\
\hline Two & & 27 & 19,3 \\
\hline Three and more & & 27 & 19,3 \\
\hline Location of the cyst in the liver & 143 & & \\
\hline Anterior segment: III, IV, V,VI & & 72 & 50.3 \\
\hline Posterior segment: I, II, VII, VIII & & 71 & 49.7 \\
\hline Maaouni's distribution of the cyst5 & 143 & & \\
\hline Cyst in the segment IV and /or I & & 14 & 9.8 \\
\hline Cyst in the Segment II and /or, III & & 31 & 21.7 \\
\hline Cyst in the Segment V and /or VI & & 13 & 9.1 \\
\hline Cyst in the Segment VII and /or VIII & & 38 & 26.6 \\
\hline Multiple cysts & & 47 & 32.9 \\
\hline Diameter of the cyst & 143 & & \\
\hline$\leq 10 \mathrm{~cm}$ & & 62 & 43.4 \\
\hline$>10 \mathrm{~cm}$ & & 81 & 56.6 \\
\hline Gharbi morphological type of the cyst & 143 & & \\
\hline 1 & & 18 & 12.6 \\
\hline II & & 22 & 15.4 \\
\hline III & & 66 & 46.2 \\
\hline IV & & 28 & 19.6 \\
\hline V & & 9 & 6.3 \\
\hline Biliary duct dilatation & 139 & 14 & 9.8 \\
\hline Other Hydatid cyst outside the liver & 142 & & \\
\hline One abdominal organ & & 128 & 90.1 \\
\hline Abdominal hydatidosis & & 11 & 7.7 \\
\hline Lung & & 3 & 2.1 \\
\hline Preoperative complications of the cyst & 143 & 41 & 28.7 \\
\hline
\end{tabular}




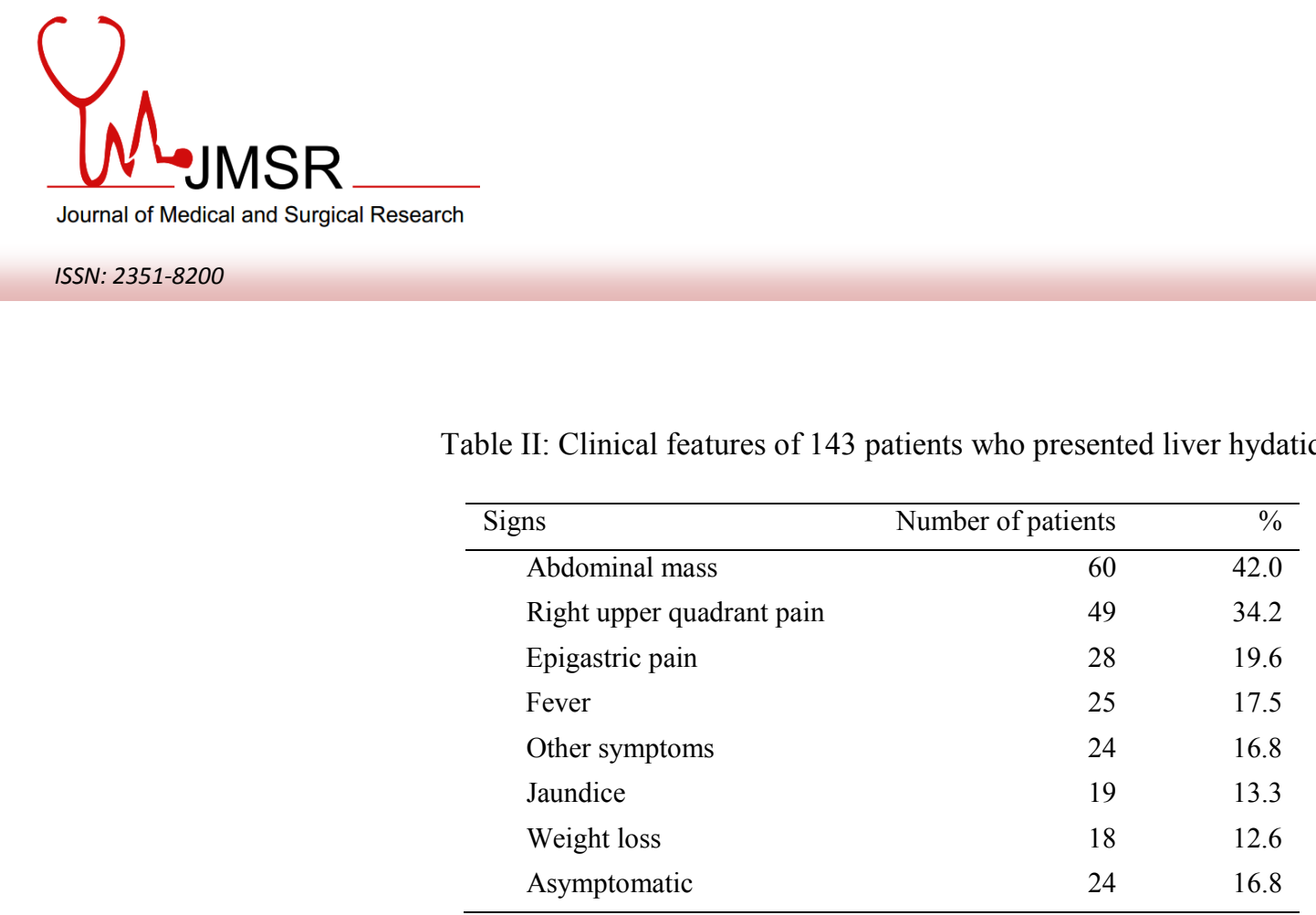

All the 143 patients were operated, 111 of them had Pericystectomy (PK) (77.6\%) and remaining 32 patients had Hepatic Resection (HR) (22.4\%). The procedure was very difficult, leading to diaphragmatic laceration, hollow viscera

Table III: Surgical procedures, operative findings and follow up on patients with liver hydatid cyst.

\begin{tabular}{lrrr}
\hline & $\begin{array}{r}\text { Number of evaluated } \\
\text { patients }\end{array}$ & Number of subject & $\%$ \\
\hline Surgical treatment & 143 & 111 & 77.6 \\
$\quad$ Pericystectomy & & 32 & 22.4 \\
$\quad$ Hepatic Resection & 143 & & \\
Cyst wall (pericyst) & & 35 & 24.5 \\
$\quad$ Soft & & 108 & 75.5 \\
$\quad$ Fibrotic or calcified & 143 & 30 & 21.0 \\
Biliary fistula & 30 & & \\
Biliary fistula treatment & & 17 & 56.7 \\
$\quad$ Suture & & 8 & 26.7 \\
$\quad$ Catheterisation & & 5 & 16.6 \\
$\quad$ Drainage & 143 & 16 & 11.2 \\
Common bile duct dilatation & 142 & 12 & 8.4 \\
Operative diaphragmatic laceration & 143 & 23 & 16.1 \\
Difficult dissection & 143 & 30 & 21.0 \\
Overall postoperative complications & 143 & 28 & 19.6 \\
Deep abdominal complications & 142 & 2 & 1.4 \\
Mortality & 141 & 9 & 6.4 \\
Recurrence & & & \\
\hline
\end{tabular}

Two death occurred in hepatic resection group after DAC due to disseminated hydatidosis with multiple associated resection and important weight loss in the first case, and severe non surgical sepsis in the other case. Over all morbidity occurred in 21 perforation and haemorrhage in 23 patients $(16 \%)$ due to the importance of inflammatory reaction and adherences. All details of the operative findings and procedures are shown in the Table III. 


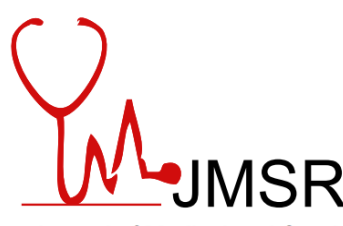

Journal of Medical and Surgical Research

$(p=0.535)$. Deep abdominal complications occurred in 19 patients $(17.1 \%)$ of Pericystectomy group and 9 patients (28.1\%) in Hepatic Resection group $(p=0.167)$. There were no significative difference between the Pericystectomy group versus Hepatic Resection group concerning recurrence and the duration of the follow up figure 1. All this data are reported in Table IV.

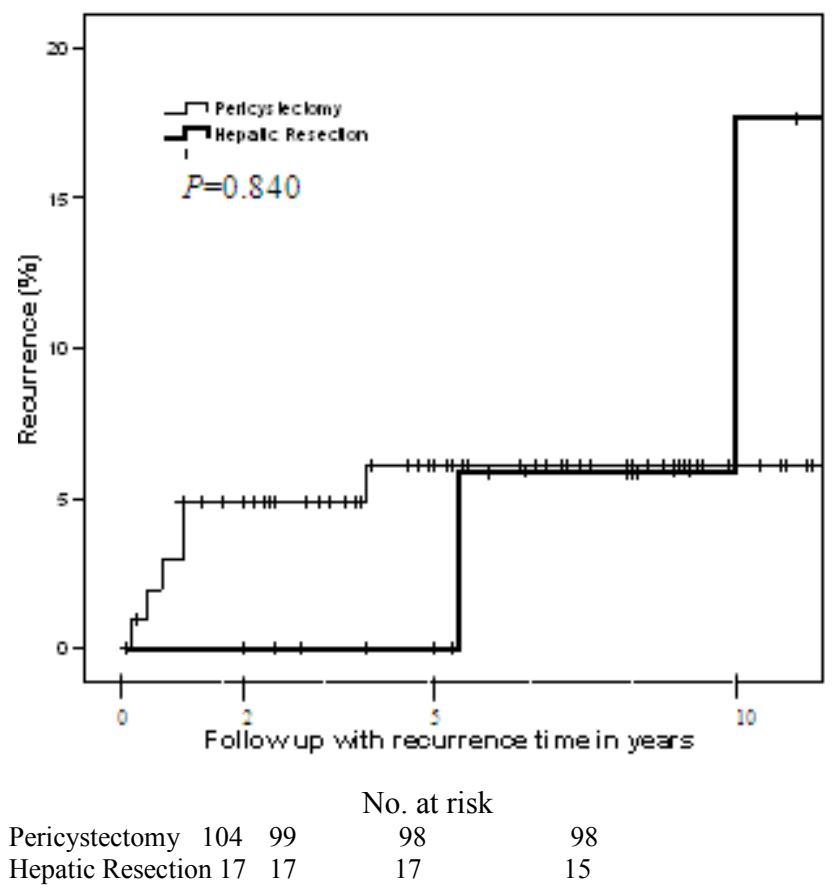

Figure 1 Kaplan-Meier analysis of rates of recurrence of liver hydatid cysts after Pericystectomy and Hepatic Resection surgical treatment. $\mathrm{P}=0.840$ (log rank test)

Table IV: Postoperative outcomes and recurrence rates.

\begin{tabular}{|c|c|c|c|}
\hline & Pericystectomy (\%) & Hepatic Resection (\%) & $P \S$ \\
\hline Overall postop. complications & $21(18.9)$ & $9(28.1)$ & $0.260 \S$ \\
\hline Deep abdominal complications & $19(17.1)$ & $9(28.1)$ & $0.167 \S$ \\
\hline Postoperative haemorrhage & $2(1.8)$ & $1(3.1)$ & $0.535^{*}$ \\
\hline Postoperative hospital stay (days) $\downarrow$ & $8(6-12)$ & $8(7-15)$ & $0.180 \#$ \\
\hline Reinterventions & $2(1.8)$ & $2(6)$ & $0.216^{*}$ \\
\hline Follow-up (months) $\dagger$ & $108(54-144)$ & $89(44-135)$ & $0.288 \#$ \\
\hline Recurrence & $7(6.3)$ & $2(6.6)$ & $0.999 *$ \\
\hline Recurrence rate $(\%)$ & & & $0.840 \dagger$ \\
\hline 2 years & $4.9 \% \pm 2.1$ & 0 & \\
\hline 5 years & $6.1 \% \pm 2.4$ & 0 & \\
\hline 10 years & $6.1 \% \pm 2.4$ & $17.6 \% \pm 12.1$ & \\
\hline
\end{tabular}

\section{DISCUSSION}

By the past, some authors supported that radical surgery of liver hydatid cyst, have less post operative complications as biliary leakage and recurrence $[8,13,14,16,17]$ but carried the highest operative risk.12, 18 Recently, it has been demonstrated that there was no statistically significant difference between radical and conservative procedures, concerning post-operative mortality, morbidity or recurrence rate.[1]This 
study contribute to assess the safety of radical surgery for liver hydatid cysts .

Most of Studies demonstrates that mortality and morbidity for radical and conservative approaches are similar. [1-3, 6, 12], Commonly LHC postoperative mortality ranges from 0 to $6.5 \%$, [1, 4 , 19] and can reach at $9.2 \%$ after radical surgery.15 This high rate is often due to preoperative complications, disseminated disease and important preoperative weight loss. $[5,19,7$, $20,21]$ The reason why, all interventions on liver hydatidosis should be considered as potentially major surgery5 and radical surgery should only be carried out by experienced hepatobiliary surgeons in terirtiary unit. Assumed risks should be balanced with patient conditions and cyst caracteristics. $[1,5$, 15]

Our data demonstrate that specific morbidity of LHC radical surgery representing by deep abdominal complication occurred in $19.6 \%$ with no statistical difference the PK group $17.1 \%$ and HR group $28.1 \%(p=0.167)$. This complication range from $10 \%$ to $29.5 \% .5-7,[19,22,23]$ Passing through healthy hepatic parenchyma allows a better identification and management of biliary fistula. [5, 24] Linear cut edge offer additional possibility of bilistasis and haemostasis. The bile leakage represents the main source of immediate postoperative complications. In the current study, postoperative haemorrhage occurred in only 2 patients of PK group 1.8\% and one patient of HR group $3.1 \% \quad(p=0.535)$. However, even this complication is rare, all precautions should be taken to ovoid its occurrence. In fact, all LHC interventions should be considered as potentially major surgery, [1] Therefore, Radical approaches in liver hydatid cyst should only be performed in tertiary units. Median hospital stay was similar (8 days) in both groups with no significant statistical differences between the PK and HR groups although other studies reported higher hospital stay of 13.8 days[15] and $17 \pm 9.2$ days. [25]

It is widely reported that recurrence rate increases with the time of the follow up.11 It becomes symptomatic 3 to 4 years after surgery. [3, 7, 21, 25] Median follow in our study exceeded 7 years, and no statistical difference was assessed comparing recurrence rate of both groups $(p=0.288)$. Some authors, [12] reported no recurrence after a Radical surgery for LHC with median follow up of only 15 months (range 1-36), knowing that a follow up of at least 5years is needed for more accurate results. [12]

Patients with hydatid liver cysts usually present a surgical challenge to surgeon staff even in endemic area. It has been demonstrated that Radical surgical resection does not prevent recurrences of liver hydatid cyst and neither reduce morbid-mortality of this surgery when compared to conservative surgery. [1, 12] Concept of radical and conservative surgery should be exceeded. Liver hydatid cyst, as a benign liver disease, should be treated with the intention of preserving healthy liver tissue, thus the management should be tailored to the patient. If a patient carries more then one cyst, surgical staff should assess the best attitude for each cyst. Combination of different therapeutic option is possible and the a same patient may undergo both Radical and Conservative approaches if needed without changing aims of this surgical management. Radical approaches should be an alternative to Conservative approaches and vice versa for each cyst these two concepts should not be in competition or opposed but need to be evaluated as a strategie. Managing liver hydatid cyst, should lead physician to take into consideration cyst's characteristics (central or peripheral location, neighbouring or not hepatic and glissonian pedicles) and to seek for biliary fistula as a matter of major decision tool. Therefore performing Radical approaches should start by opening the cyst after field protection, to decompress it's content and make easier liver mobilization. This step offers the opportunity to look for biliary fistula in side the cavity and assess the thikness of the pericyst. Then the decision to perform a total perycystectomy or hepatic resection can be taken. Otherwise, in case of large cysts located deeply in liver or appended to major vascular-biliary structures of the liver, posterior cysts or in patient with altered statement, the decision of unroofing the cyst combined to one of various procedures of residual cavity management can be hold. It have been reported a helpful scoring system to direct patient to an experienced surgeon in hepato-biliary surgery unit.5 Five items are to assess: presence of preoperative complications of the cyst, 3 or more cysts in the liver, biliary fistula, thick pericyst, and capitonage. Patients with none of this factors or only one, can be operated in any surgical unit. In case of presence of two or more of this factors the patient should be directed to tertiary unit. Since both approach (Radiacal and conservative) offer similar results, this scoring system can be used to select patients in tertiary unit to be included liver resection in surgeon residency program. 


\section{ACKNOWLEDGEMENTS}

The authors acknowledge Z. Ouazzani Touhami for her patience and support.

\section{REFERENCES}

1. H. O. El Malki, A. Souadka, A. Benkabbou, R. Mohsine, L. Ifrine, R. Abouqal, A. Belkouchi. Radical versus conservative surgical treatment of liver hydatid cysts. Br J Surg 2014; 101 ( 6): 669675

2. Chautems R, Bühler LH, Gold B, Giostra E, Poletti P, Chilcott M, Morel P, Mentha G. Surgical management and long-term outcome of complicated liver hydatid cysts caused by Echinococcus granulosus. Surgery 2005; 137: 312-6.

3. Kapan M, Kapan S, Goksoy E, Perek S, Kol E. Postoperative recurrence in hepatic hydatid disease. J Gastrointest Surg 2006; 10: 734-9.

4. Majbar MA, Souadka A, Sabbah F, Raiss M, Hrora A, Ahallat M. Peritoneal echinococcosis: anatomoclinical features and surgical treatment. World J Surg. 2012 May;36(5):1030-5.

5. Daradkeh S, El-Muhtaseb H, Farah G, Sroujieh AS, Abu-Khalaf M. Predictors of morbidity and mortality in the surgical management of hydatid cyst of the liver. Langenbecks Arch Surg 2007; 392: 359.

6. El Malki HO, El Mejdoubi Y, Souadka Am, Mohsine R, Ifrine L, Abouqal R, Belkouchi A. Predictive Factors of Deep Abdominal Complications after Operation for Hydatid Cyst of the Liver: 15 Years of Experience with 672 Patients. J Am Coll Surg 2008; 206: 629-37.

7. Gollackner B, Langle F, Auer H, Maier A, Mittlbock M, Agstner I, Karner J, Langer F, Aspock H, Loidolt H, Rockenschaub S, Steininger R. Radical surgical therapy of abdominal cystic hydatid disease: factors of recurrence. World J Surg 2000; 24: 717-21.

8. Agaoglu N, Turkyilmaz S, Arslan MK. Surgical treatment of hydatid cysts of the liver. Br J Surg 2003; 90:1536-41.

9. Safioleas M, Misiakos E, Manti C, Katsikas D, Skalkeas G. Diagnostic evaluation and surgical management of hydatid disease of the liver. World J Surg 1994; 18: 859-65.

10. Akgun Y, Yilmaz G. Efficiency of obliteration procedures in the surgical treatment of hydatid cyst of the liver. ANZ J Surg 2004; 74: 968-73.

11. Atmatzidis KS, Pavlidis TE, Papaziogas BT, Mirelis C, Papaziogas TB. Recurrence and long-term outcome after open cystectomy with omentoplasty for hepatic hydatid disease in an endemic area. Acta Chir Belg 2005; 105: 198-202.

12. El Malki HO, El Mejdoubi Y, Souadka A, Zakri B, Mohsine R, Ifrine L, Abouqal R, Belkouchi A. Does primary surgical management of liver hydatid cyst influence recurrence? J Gastrointest Surg. 2010; 14 (7): 1121-7.
13. Yüksel O, Akyürek N, Sahin T, Salman B, Azili C, Bostanci H. Efficacy of radical surgery in preventing early local recurrence and cavity-related complications in hydatic liver disease. J Gastrointest Surg. 2008; 12 (3): 483-9.

14. Dervenis C, Delis S, Avgerinos C, Madariaga J, Milicevic M. Changing concepts in the management of liver hydatid disease. J Gastrointest Surg. 2005 Jul-Aug;9(6): 869-77.

15. Akbulut S, Senol A, Sezgin A, Cakabay B, Dursun M, Satici O. Radical vs conservative surgery for hydatid liver cysts: experience from single center. World J Gastroenterol 2010; 16: 953-959.

16. Tagliacozzo S, Miccini M, Amore Bonapasta S, Gregori M, Tocchi A. Surgical treatment of hydatid disease of the liver: 25 years of experience. Am J Surg 2011; 201: 797-804.

17. Sahin M, Kartal A, Haykir R, Cakir M. RF-assisted cystectomy and pericystectomy: a new technique in the treatment of liver hydatid disease. Eur Surg Res. 2006;38(2):90-3.

18. Sayek I, Onat D. Diagnosis and treatment of uncomplicated hydatid cyst of the liver. World $\mathrm{J}$ Surg 2001; 25: 21-7.

19. Chautems R, Buhler L, Gold B, Chilcott M, Morel P, Mentha G. Long term results after complete or incomplete surgical resection of liver hydatid disease. Swiss Med Wkly. 2003 May 3; 133(17-18): 258-62.

20. Yagci G, Ustunsoz B, Kaymakcioglu N, Bozlar U, Gorgulu S, Simsek A, Akdeniz A, Cetiner S, Tufan T. Results of surgical, laparoscopic, and percutaneous treatment for hydatid disease of the liver: 10 years experience with 355 patients. World J Surg 2005; 29: 1670-9.

21. Yorganci K, Sayek I. Surgical treatment of hydatid cysts of the liver in the era of percutaneous treatment. Am J Surg 2002; 184: 63-9.

22. Bülbüller N, Ilhan YS, Kirkil C, Yeniçerioğlu A, Ayten R, Cetinkaya Z. The results of surgical treatment for hepatic hydatid cysts in an endemic area. Turk J Gastroenterol 2006; 17: 273-278.

23. Balik AA, Başoglu M, Celebi F, Oren D, Polat KY, Atamanalp SS, Akçay MN. Surgical treatment of hydatid disease of the liver: review of 304 cases. Arch Surg 1999; 134: 166-9.

24. Kayaalp C, Sengul N, Akoglu M. Importance of cyst content in hydatid liver surgery. Arch Surg. 2002; 137 (2): 159-63.

25. El Malki HO, El Mejdoubi Y, Souadka Am, Mohsine R, Ifrine L, Abouqal R, Belkouchi A. Predictive model of biliocystic communication in liver hydatid cysts using classification and regression tree analysis. BMC Surg. 2010 Apr 16; 10:16.

26. Safioleas MC, Misiakos EP, Kouvaraki M, Stamatakos MK, Manti CP, Felekouras ES. Hydatid disease of the liver: a continuing surgical problem. Arch Surg 2006; 141: 1101-1108. 